\title{
Impact of climatic factors on the release of $E-\beta$ - caryophyllene from alginate beads
}

\author{
Frédéric Daems ${ }^{(1)}$, François Béra ${ }^{(2)}$, Stéphanie Lorge ${ }^{(3)}$, Christophe Fischer ${ }^{(4)}$, \\ Yves Brostaux ${ }^{(5)}$, Frédéric Francis ${ }^{(6)}$, Georges Lognay ${ }^{(4)}$, Stéphanie Heuskin ${ }^{(4)}$
}

(1) Walloon Agricultural Research Centre. Valorisation of Agricultural Products Department. Chaussée de Namur, 24. BE-5030 Gembloux (Belgium).E-mail: f.daems@cra.wallonie.be

(2) University of Liège - Gembloux Agro-Bio Tech. Agro-Bio Chem Department. Food Science Unit. Passage des Déportés, 2. BE-5030 Gembloux (Belgium).

(3) Bureau d'études environnement et analyses (BEAGx). Passage des Déportés, 2. BE-5030 Gembloux (Belgium).

(4) University of Liège - Gembloux Agro-Bio Tech. Agro-Bio Chem Department. Analytical Chemistry Unit. Passage des Déportés, 2. BE-5030 Gembloux (Belgium).

(5) University of Liège - Gembloux Agro-Bio Tech. Statistics, Mathematics and Applied Computer Sciences, Agro-Bio Chem Department. Passage des Déportés, 2. BE-5030 Gembloux (Belgium).

(6) University of Liège - Gembloux Agro-Bio Tech. Agro-Bio Chem Department. Functional and Evolutionary Entomology Unit. Passage des Déportés, 2. BE-5030 Gembloux (Belgium).

Received on December 10, 2014; accepted on December 15, 2015.

Description of the subject. Alginate beads that release semiochemical compounds are interesting biological control devices used to attract the natural enemies of aphids in infested crops. Little information, however, is available about the impact of climatic factors on the release of semiochemicals from this diffusive system.

Objectives. The objective of this scoping study was to investigate the impact of temperature, relative humidity and wind speed, on the release of $E$ - $\beta$-caryophyllene from alginate beads.

Method. The impact of the three climatic factors on the release of $E-\beta$-caryophyllene from alginate beads was evaluated using a Box-Behnken experimental design and a laboratory scale volatile collection system. The influence of relative humidity on bead water content and size, with and without this semiochemical, was also investigated using a gravimetric method and an easy-to-use photographic device, respectively.

Results. The results showed that an increase in temperature caused a significant increase in the $E$ - $\beta$-caryophyllene release rate. Neither relative humidity nor airflow, however, had a significant effect on the release of this semiochemical when relative humidity and wind speed ranged from $33 \%$ to $75 \%$ and from $6.61 \times 10^{-4} \mathrm{~m} \cdot \mathrm{s}^{-1}$ to $2.05 \times 10^{-2} \mathrm{~m} \cdot \mathrm{s}^{-1}$, respectively. The isotherm curves obtained were characteristic of food products and biopolymer materials. The isotherm shapes were not modified by the incorporation of the semiochemical into alginate beads, and showed an important increase in water content when relative humidity values exceeded $85 \%$. Fortunately, this water content increase did not affect bead size, which facilitates the calculation of $E$ - $\beta$-caryophyllene release.

Conclusions. The present study shows for the first time the impact of the three main climatic factors on the release of $E-\beta$ caryophyllene from alginate beads. It allows learning more about how these biological control devices operate in order to optimize future field trials.

Keywords. Controlled release, biological pest control, alginate, $E$ - $\beta$-caryophyllene, climatic factors, sorption.

\section{Impact des facteurs climatiques sur la diffusion du $E$ - $\beta$-caryophyllène à partir de billes d'alginate}

Description du sujet. Les billes d'alginate libérant des substances sémiochimiques sont des dispositifs de lutte biologique intéressants utilisés pour attirer les ennemis naturels des pucerons dans les cultures infestées. Cependant, peu d'informations sont disponibles quant à l'impact des facteurs climatiques sur l'émission des sémiochimiques à partir de ce système de diffusion. Objectifs. L'objectif de cette étude exploratoire était d'étudier l'impact de la température, de l'humidité relative et de la vitesse du vent sur la diffusion de l' $E$ - $\beta$-caryophyllène à partir de billes d'alginate.

Méthode. L'impact des trois facteurs climatiques sur la diffusion de l'E- $\beta$-caryophyllène à partir de billes d'alginate a été évalué en utilisant un plan d'expérience de type Box-Behnken et un système en laboratoire de collecte des composés volatils. 
L'influence de l'humidité relative sur la teneur en eau et la taille des billes, avec ou sans le sémiochimique, a également été étudiée en utilisant une méthode gravimétrique et un dispositif photographique facile à concevoir.

Résultats. Les résultats ont montré qu'une augmentation de la température provoque une augmentation significative du taux de diffusion de l' $E$ - $\beta$-caryophyllène. Par contre, l'humidité relative et la vitesse du vent n'ont aucun effet significatif sur la libération de ce sémiochimique dans la gamme de mesures sélectionnée : allant de $33 \%$ à $75 \%$ pour l'humidité relative et de $6,61 \times 10^{-4} \mathrm{~m} \cdot \mathrm{s}^{-1}$ à $2,05 \times 10^{-2} \mathrm{~m} \cdot \mathrm{s}^{-1}$ pour la vitesse du vent. Les courbes d'isothermes de sorption obtenues étaient caractéristiques de la plupart des produits alimentaires et des biopolymères. Les formes des isothermes n'ont pas été modifiées par l'incorporation du sémiochimique dans les billes d'alginate et elles ont montré une augmentation importante de leur teneur en eau lorsque l'humidité relative dépassait les $85 \%$. Heureusement, cette augmentation de la teneur en eau n'a pas affecté la forme des billes, ce qui facilite le calcul du taux de diffusion de ce sémiochimique.

Conclusions. Cette étude présente pour la première fois l'impact de trois principaux facteurs climatiques sur la diffusion de $l^{\prime} E-\beta$-caryophyllène à partir des billes d'alginate. Elle permet de mieux comprendre le fonctionnement de ces dispositifs de lutte biologique afin d'optimiser les futurs essais sur le terrain.

Mots-clés. Diffusion contrôlée, lutte biologique, alginate, $E$ - $\beta$-caryophyllène, facteurs climatiques, sorption.

\section{INTRODUCTION}

For many years, in order to reduce pesticide use, integrated pest management (IPM) strategies have been developed to protect crops from pest insects (Kogan, 1998; Witzgall, 2001; Horst, 2013). The term "semiochemicals" refers to the chemical communication signals that are emitted by living organisms and that induce physiological or behavioral changes in other individuals (Cox, 2004; Reddy et al., 2004; Tapia et al., 2010). The use of semiochemicals release devices in infested fields to attract natural insect enemies of a target pest is a promising biological control weapon (Heuskin et al., 2011). Currently, there are two main types of slow-release dispensers on the market: liquid formulations with a permeable diffusion area or spray-system (Byers, 1988; Hofmeyr et al., 1995; Torr et al., 1997; Atterholt et al., 1999; De Vlieger, 2001; Welter et al., 2005; Shem et al., 2009) and solid matrix dispensers (Golub et al., 1983; Lopez et al., 1991; McDonough, 1991; Kehat et al., 1994; Tomaszewska et al., 2005; Cork et al., 2008; Zhang et al., 2008). In recent years, as a result of ecological concerns, researchers and manufacturers have developed environmentally friendly and efficient slow-release formulations with inert biodegradable polymers such as alginate (Hennesy et al., 2004; Yosha et al., 2008; Zada et al., 2009; Heuskin et al., 2012a).

Alginate is a natural biodegradable polymer extracted from brown algae and composed of two monomeric units, $\beta$-D-mannuronic acid and $\alpha$-Lguluronic acid. In the presence of divalent cations, this soluble polysaccharide forms a gel in which the density is related mainly to the proportion and organization of the mannuronic and guluronic acid units (Velings et al., 1995; Draget et al., 1997; Davis et al., 2003). In the food industry, alginate gel beads are seen as efficient releasers of volatile aroma and flavor compounds (Malone et al., 2003; Hambleton et al., 2011), and essential oils that act as antimicrobial agents (Chang et al., 2003; Lai et al., 2007). Various compounds can easily be incorporated into the permeable solid polymeric network of alginate gel and released over time. The release kinetic of a volatile compound incorporated into alginate beads depends on several parameters, such as type and concentration of the alginate, type and concentration of the divalent cation used for the gelation process, and the physicochemical properties of the encapsulated active compound (Velings et al., 1995; Alhmedi et al., 2010; Hambleton et al., 2011).

$E$ - $\beta$-caryophyllene is a sesquiterpene that is produced by plants to attract the natural enemies of aphids (Sasso et al., 2009; Alhmedi et al., 2010; Heuskin et al., 2011). It also has the effect of reducing aphid reproduction (Tomova et al., 2005). In field trials, Heuskin et al. (2012a, 2012b) demonstrated the efficiency of using alginate beads as $E$ - $\beta$-caryophyllene releasers to attract aphid parasitoids and predators. This slow-release device was manufactured in accordance with biological control requirements (Yosha et al., 2008; Heuskin et al., 2012a). Additional advantages are that alginate beads are simple to produce at the laboratory scale, are easy to manipulate and have low oxygen permeability, thus protecting sesquiterpenes from oxidation (Heuskin et al., 2010).

Although the alginate beads semiochemical slowrelease device were successfully used in field trials conducted by Heuskin et al. (2012b), the impact of climatic factors on the beads' release mechanism remained unclear. To date, only a few studies have investigated the use of alginate beads as a semiochemical release device in biological control (Yosha et al., 2008; Heuskin et al., 2012b). Some studies of other release devices have shown that climatic factors could have a significant effect on their diffusion mechanism and should not be ignored in terms of device optimization (Van der Kraan et al., 1990; Suckling et al., 1999; Atterholt et al., 1999; Shem et al., 2009; Zhu et al., 2015). 
In order to optimize future field trials and learn more about how alginate beads with $E$ - $\beta$-caryophyllene perform in the field, it was necessary to gain a better understanding of the impact of climatic factors on this biological slow-release device. This scoping study therefore sought to investigate, simultaneously and at the laboratory scale, the impact of the three main climatic factors - temperature, relative humidity (RH) and wind speed - on the release of $E$ - $\beta$-caryophyllene from alginate beads, using an experimental design. The influence of RH on bead size and water content was also investigated for the first time in order to learn more about this device and explain observations made in the first experiment.

\section{MATERIALS AND METHODS}

\subsection{Chemicals and reagents}

$E$ - $\beta$-caryophyllene (purity $\sim 97 \%$ ) was extracted using flash chromatography from the essential oil Nepeta cataria, as reported by Heuskin et al. (2010). The oil was purchased from Essential7.com (Roswell, NM, USA, lot no. EO0020f) and originated from Canada. The $n$-butyl-benzene, used as internal standard (IS), was purchased from Sigma-Aldrich (Bornem, Belgium). The $n$-Hexane (GLC-Pesticide residue grade $>95 \%$ ) and $n$-pentane extra pure were purchased from Fischer Scientific (Leicestershire, UK).

For the alginate bead formulation, sodium alginate and $\alpha$-tocopherol were purchased from Sigma-Aldrich (Bornem, Belgium), calcium chloride from Acros Organics (Geel, Belgium) and sunflower oil from a local supermarket.

\section{2. $E$ - $\beta$-caryophyllene alginate bead formulation}

The alginate beads were formulated as described by Heuskin et al. (2012a). Briefly, $8 \mathrm{ml}$ of sodium alginate $(1.5 \% \mathrm{w} / \mathrm{v}), 1.8 \mathrm{ml}$ of sunflower oil, $0.2 \mathrm{~g}$ of $E-\beta$ caryophyllene and $150 \mathrm{mg}$ of $\alpha$-tocopherol were mixed using an Ultraturax system (IKA T18 Basic, QLab, Vilvoorde, Belgium) at 24,000 rpm for $20 \mathrm{~s}$ in order to obtain a homogeneous emulsion. This emulsion was extruded through a needle $(0.4 \mathrm{~mm}$ I.D.) and the droplets fell into an agitated (magnetic stir bar at $300 \mathrm{rpm}$ ) calcium chloride solution $(0.2 \mathrm{M})$, forming alginate gel beads containing the $E$ - $\beta$-caryophyllene. The flow rate in the Tygon ${ }^{\circledR}$ tube carrying the emulsion to the needle was set at $1.25 \mathrm{ml} \cdot \mathrm{min}^{-1}$. The beads were kept for $48 \mathrm{~h}$ in the calcium chloride solution in order to stabilize the syneresis phenomenon. They were then dried to eliminate surface water and subjected to air pressure at 2 bars for $30 \mathrm{~min}$ at $21^{\circ} \mathrm{C} \pm 2{ }^{\circ} \mathrm{C}$. The dried beads were stored in darkness in an airtight container at $4{ }^{\circ} \mathrm{C}$.

\subsection{Quantification of $\boldsymbol{E}$ - $\boldsymbol{\beta}$-caryophyllene}

The amount of $E$ - $\beta$-caryophyllene released by the alginate formulation was quantified using the UltraFast GC-FID analytical method validated according to the accuracy profile procedure described by Heuskin et al. (2010), with the same apparatus and under the same conditions. Briefly, analyses were conducted on a Thermo Ultra-Fast Trace GC operated with a split/ splitless injector and a Thermo AS 3,000 autosampler (Thermo Electron Corp., Interscience, Louvain-laNeuve, Belgium). The GC system was equipped with an Ultra-Fast Module (UFM) incorporating a direct resistively heated column (Thermo Electron Corp., UFC-5, 5\% phenyl, $5 \mathrm{~m} \times 0.1 \mathrm{~mm}$ I.D., $0.1 \mu \mathrm{m}$ film thickness). The injection volume and temperature were set at $1 \mu 1$ and $240{ }^{\circ} \mathrm{C}$, respectively. A split ratio 1:100 was applied. Helium (He) was selected as the carrier gas and was introduced into the GC system with a constant flow rate of $0.5 \mathrm{ml} \cdot \mathrm{min}^{-1}$. The temperature program for UFM was: initial temperature at $40^{\circ} \mathrm{C}$, held for $0.1 \mathrm{~min}$, ramp 1 at $30^{\circ} \mathrm{C} \cdot \mathrm{min}^{-1}$ to $95^{\circ} \mathrm{C}$, ramp 2 at $35^{\circ} \mathrm{C} \cdot \mathrm{min}^{-1}$ to $155^{\circ} \mathrm{C}$, ramp 3 at $200{ }^{\circ} \mathrm{C}$. $\min ^{-1}$ to $280{ }^{\circ} \mathrm{C}$, final hold of $0.5 \mathrm{~min}$ at $280{ }^{\circ} \mathrm{C}$, for a total run time of $4.78 \mathrm{~min}$. The GC unit had a high frequency fast flame ionization detector (300Hz FID), set at $250{ }^{\circ} \mathrm{C}$. Air flow, $\mathrm{H}_{2}$ flow and makeup gas flow $\left(\mathrm{N}_{2}\right)$ were set at 350,35 and $30 \mathrm{ml} \cdot \mathrm{min}^{-1}$, respectively. The data were processed using Chromcard software (version 2.3.3).

\subsection{Impact of climatic factors on alginate beads}

Volatile collection system. In order to measure the release rate of $E$ - $\beta$-caryophyllene from the alginate beads, we developed a sealed and easy-to-use volatile collection system (VCS) (Figure 1a). The system revolved around a double funnel-shaped device. The lower funnel was made of glass and had a sintered surface $\left(12.6 \mathrm{~cm}^{2}\right)$ on which the alginate beads (200 mg) were deposited, and the upper funnel was made of Teflon (Isoflon, Diemoz, France). The funnels were fastened tightly together with Teflon tape and a metallic clamp. The air was sucked out with a vacuum pump (Vacuubrand RZ5, Analis, Namur, Belgium) connected to the top of the device. This homemade VCS allows airflow to be controlled and keeps it constant during experiments. The air bubbled in a supersaturated saline solution (magnesium chloride, magnesium nitrate or sodium chloride to achieve relative humidity of 33,53 and $75 \%$, respectively) and went through the funnel devices, flowing uniformly around the beads and extracting volatile compounds. $E$ - $\beta$-caryophyllene molecules released by the alginate formulation were retained in two adsorbent cartridges (collection and security traps). 


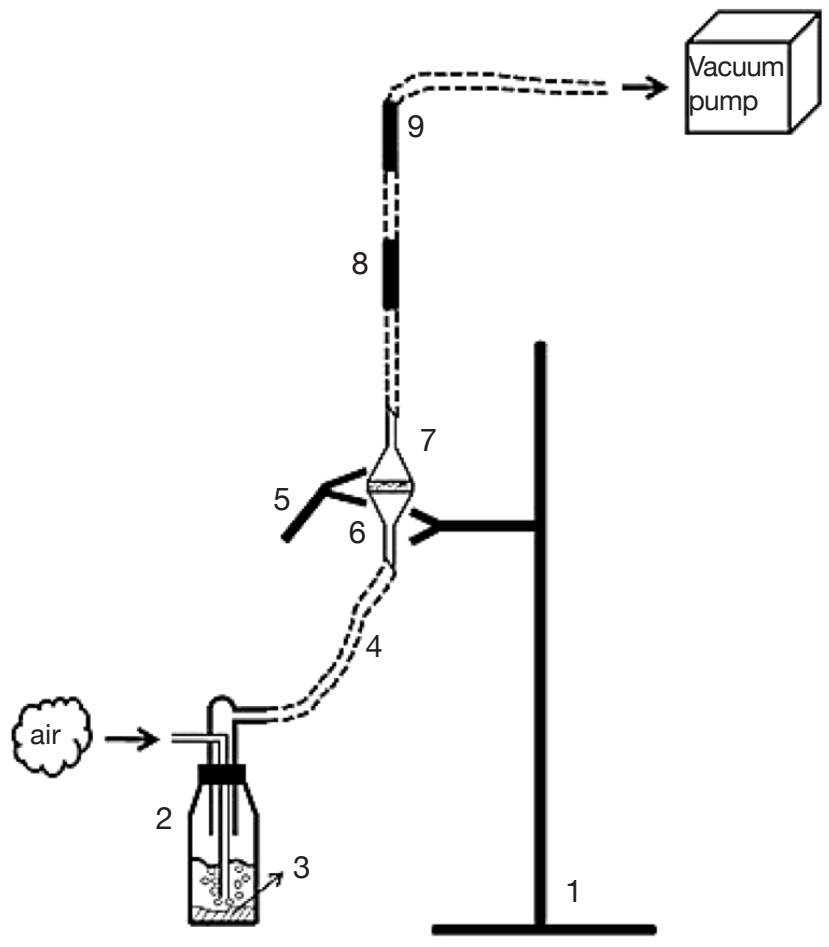

Figure 1a. Diagram of the volatile collection system (VCS) - Schéma du dispositif expérimental de collection des composés volatiles.

1: statif (pedestal) - statif; 2: Schott bottle (500 ml) - flacon Schott en verre $(500 \mathrm{ml})$; 3: supersaturated saline solution (magnesium chloride, 33\%; magnesium nitrate, 53\%; sodium chloride, $75 \%$ ) - solution saline saturée (chlorure de magnésium, $33 \%$; nitrate de magnésium, $53 \%$; chlorure de sodium, $75 \%$ ); 4: Teflon tube - tube en téflon; 5 : metallic clamp - pince métallique; 6: glass funnel-shaped device - entonnoir en verre; 7: Teflon funnel-shaped device - entonnoir en téflon; 8: collection cartridge - cartouche absorbante; 9: security cartridge - cartouche absorbante de sécurité.

The cartridges consisted of $60 \mathrm{mg}$ of HayeSep Q (80-100 mesh; Alltech, Lokeren, Belgium) adsorbent packed in Teflon tubing (4 mm I.D. $\times 1 \mathrm{~mm}$ wall thickness) between two pieces of stainless steel (AISI 304) wire cloth (325 mesh; Haver Belgium S.A., Battice, Belgium) and two glass tubes $(4 \mathrm{~mm}$ O.D. $\times 0.8 \mathrm{~mm}$ wall thickness). The cartridges were changed regularly (max. $48 \mathrm{~h}$ ) to prevent saturation of the adsorbent, which would result in a breakthrough phenomenon. The pump was switched off only when the trap cartridges were changed (this took less than $5 \mathrm{~min}$ ). After collection, each adsorbent trap (collection and security traps) was eluted four times with $250 \mu 1$ $n$-hexane, and $10 \mu \mathrm{l}$ of the internal standard solution ( $n$-butyl-benzene at $20 \mu \mathrm{g} \cdot \mu \mathrm{l}^{-1}$ in $n$-hexane) were then added to each elution sample before quantification using Fast GC-FID.
The VCS was in a thermally controlled room (Maxi Artic Jouan, Vel, Louvain-la-Neuve, Belgium) programmed at different temperatures in accordance with the experimental design. All the tubes and connections were made of Teflon in order to prevent a loss of $E$ - $\beta$-caryophyllene through adsorption by the VCS walls (Tomaszewska et al., 2005).

Estimation of diffusion coefficient. The $E-\beta$ caryophyllene release rates were measured under various experimental conditions in order to evaluate the impact of temperature, $\mathrm{RH}$ and wind speed on the diffusion of $E$ - $\beta$-caryophyllene from the alginate beads. In each case, the diffusion coefficient was estimated according to the theoretical equation of diffusion in a sphere (Eq. 1) (Cranck, 1975):

$$
\frac{M_{t}}{M_{\infty}}=1-\frac{6}{\pi^{2}} \sum_{n=1}^{\infty} \frac{1}{n^{2}} \exp \left(-\frac{D n^{2} \pi^{2} t}{a^{2}}\right)
$$

where $M_{t}($ in $\mu \mathrm{g}$ ) is the cumulative quantity of $E-\beta$ caryophyllene released at time $t ; M_{\infty}$ (in $\mu \mathrm{g}$ ) is the cumulative quantity of $E$ - $\beta$-caryophyllene released at time $\infty$ (taken as the total quantity of $E$ - $\beta$-caryophyllene incorporated into a bead at time $t=0$ ); $a$ (in $\mathrm{m}$ ) is the radius of one bead; $t$ (in s) is the diffusion time; $n$ is

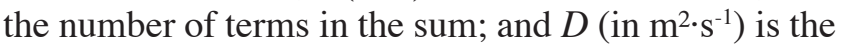
effective diffusion coefficient. The diffusion coefficient was approximated at a value that minimized the sum square between the experimental and theoretical $M /$ $M_{\infty}$ values, using the Excel Solver tool (v. 2003). $M_{t}$ was determined by the amount of $E$ - $\beta$-caryophyllene retained in the trap cartridges. The quantity of $E-\beta$ caryophyllene in the beads at time $T_{0}\left(M_{\infty}\right)$ was determined according to the protocol proposed by Heuskin et al. (2012b).

The equation was applied to the beads based on the following assumptions:

- diffusion occurred in a non-steady state;

- the $E$ - $\beta$-caryophyllene surface concentration was constant over time and equal to zero;

- the bead radius was constant (Cranck, 1975; Heuskin et al., 2012b).

Slow-release experimental design. A Box-Behnken experimental design was generated using JMP®7 software, focusing on three climatic factors temperature $\left(X_{1}\right)$, RH $\left(X_{2}\right)$ and wind speed $\left(X_{3}\right)$, each at three levels (Table 1). The experimental design consisted of 15 tests carried out randomly. Three replicates of the central point of the design $\left(25^{\circ} \mathrm{C}\right.$, $53 \% \mathrm{RH}$ and $1.06 \times 10^{-2} \mathrm{~m} \cdot \mathrm{s}^{-1}$ ) were included in the experiments. Each test lasted for two weeks.

The RH values $(33,53$ and $75 \%)$ were fixed with supersaturated solutions of magnesium chloride 
Table 1. Box-Behnken experimental design based on three abiotic factors - Plan d'expérience de Box-Behnken pour les trois facteurs abiotiques.

\begin{tabular}{|c|c|c|c|c|}
\hline Run & $X_{1}^{\mathrm{a}}$ Temperature $\left({ }^{\circ} \mathrm{C}\right)$ & $X_{2}^{\text {a }}$ Relative humidity (\%) & $X_{3}{ }^{a}$ Wind speed $\left(\mathrm{m} \cdot \mathrm{s}^{-1}\right)$ & $\begin{array}{l}Y^{\mathrm{b}} \boldsymbol{E} \text { - } \beta \text {-caryophyllene } \\
\text { diffusion coefficient }\left(\mathrm{m}^{2} \cdot \mathrm{s}^{-1}\right)\end{array}$ \\
\hline 1 & 10 & 33 & $1.06 * 10^{-2}$ & $1.82 * 10^{-14}$ \\
\hline 2 & 40 & 33 & $1.06 * 10^{-2}$ & $5.63 * 10^{-14}$ \\
\hline 3 & 10 & 75 & $1.06 * 10^{-2}$ & $7.16^{*} 10^{-15}$ \\
\hline 4 & 40 & 75 & $1.06 * 10^{-2}$ & $1.13 * 10^{-14}$ \\
\hline 5 & 10 & 53 & $6.61 * 10^{-4}$ & $6.03 * 10^{-15}$ \\
\hline 6 & 40 & 53 & $6.61 * 10^{-4}$ & $3.45^{*} 10^{-14}$ \\
\hline 7 & 10 & 53 & $2.05 * 10^{-2}$ & $1.17 * 10^{-14}$ \\
\hline 8 & 40 & 53 & $2.05 * 10^{-2}$ & $4.96 * 10^{-14}$ \\
\hline 9 & 25 & 33 & $6.61 * 10^{-4}$ & $2.00 * 10^{-15}$ \\
\hline 10 & 25 & 75 & $6.61 * 10^{-4}$ & $7.26 * 10^{-15}$ \\
\hline 11 & 25 & 33 & $2.05 * 10^{-2}$ & $1.32 * 10^{-14}$ \\
\hline 12 & 25 & 75 & $2.05 * 10^{-2}$ & $1.11 * 10^{-14}$ \\
\hline 13 & 25 & 53 & $1.06 * 10^{-2}$ & $2.27 * 10^{-14}$ \\
\hline 14 & 25 & 53 & $1.06 * 10^{-2}$ & $8.30 * 10^{-15}$ \\
\hline 15 & 25 & 53 & $1.06 * 10^{-2}$ & $1.19 * 10^{-14}$ \\
\hline
\end{tabular}

a: independent variables - variables indépendantes; ${ }^{\text {b: }}$ diffusion coefficient of $E$ - $\beta$-caryophyllene obtained with Eq. 1 - coefficient de

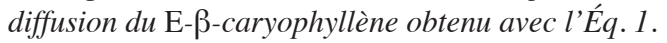

(Sigma-Aldrich, Bornem, Belgium), magnesium nitrate (Merck, Darmstadt, Germany) and sodium chloride (Merck, Darmstadt, Germany), respectively (Rao et al., 1995). The RH and temperature inside the device were checked over a period of $48 \mathrm{~h}$ before the experiment began, using a Hobo data logger (Miravox, Hoevenen, Belgium). Airflow (and therefore wind speed) was controlled daily using a flow meter Defender 520 (Bios International Corp.).

Determination of alginate bead sorption isotherms. Preliminary tests were conducted in order to ensure that any alginate bead weight loss in an oven could be attributed to water evaporation. Two types of alginate beads (with and without $E$ - $\beta$-caryophyllene), as well as the bead constituents (sunflower oil, $\alpha$-tocopherol, alginate powder and alginate solution), were placed in an oven at $100 \pm 1{ }^{\circ} \mathrm{C}$ for $6 \mathrm{~h}(\mathrm{n}=3)$.

After this step, 72 airtight containers with alginate beads ( $6 \mathrm{RH}$ values $\times 2$ alginate bead types [blank and with $E$ - $\beta$-caryophyllene] $\times 3$ replicates $\times 2$ for adsorption and desorption isotherms) were prepared. A small piece of mesh was placed inside each plastic container (vol.: $200 \mathrm{ml}$, DBP Plastic N.V., Anvers, Belgium) to prevent contact between the plastic cups containing the alginate beads and the supersaturated solutions (Figure 1b). The six supersaturated salt solutions were: potassium acetate, potassium carbonate,

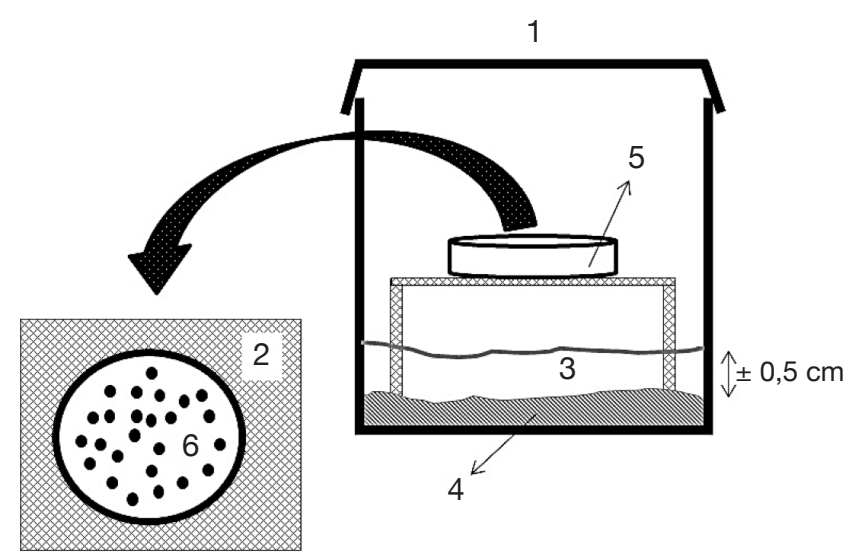

Figure 1b. Diagram of the airtight container created to derive the sorption isotherms - Schéma d'un récipient hermétique utilisé pour la réalisation des isothermes de sorption.

1: airtight container - récipient hermétique; 2 : piece of mesh - treillis; 3: distilled water - eau distillée; 4: salt (potassium acetate, $23 \%$; potassium carbonate, $43 \%$; magnesium nitrate, $53 \%$; sodium chloride, $75 \%$; potassium chloride, $85 \%$; potassium nitrate, $95 \%$ ) - sel (acétate de potassium, $23 \%$; carbonate de potassium, $43 \%$; nitrate de magnésium, $53 \%$; chlorure de sodium, $75 \%$; chlorure de potassium, $85 \%$; nitrate de potassium, $95 \%$ ); 5: plastic cup - cupule en plastique; 6 : alginate beads - billes d'alginate. 
magnesium nitrate, sodium chloride, potassium nitrate (all from Merck, Darmstadt, Germany) and potassium chloride (Chem-Lab N.V., Zedelgem, Belgium), which fixed the RH values at 23,43, 53, 75, 95 and $85 \%$, respectively. These supersaturated solutions were prepared by mixing a large excess of salt in deionized water. After this preparation, a thin layer of salt was present in the bottom of the plastic container. In order to avoid microbial contamination at $\mathrm{RH}>60 \%, 0.1 \mathrm{~g}$ thymol was put into the airtight containers (Baucour et al., 2000; Arlabosse et al., 2003; Ferrasse et al., 2004). The RH value in the containers was checked using Aqualab CX3 (Wilten, Berchem/Antwerp, Belgium) and the results were consistent with those predicted by Rao et al. (1995).

Before implementing the experiment, alginate beads with and without (blank) $E$ - $\beta$-caryophyllene were placed in a chamber at $20 \pm 1{ }^{\circ} \mathrm{C}$ with a supersaturated solution of lithium chloride (RH $11 \%$ ) or distilled water (RH 100\%) for the adsorption and desorption isotherms, respectively. This step was necessary in order to obtain homogeneous beads with the same water content. When the bead weights were stabilized, $0.7 \pm 0.2 \mathrm{~g}$ of them were placed in plastic cups in the supersaturated salt solutions in the containers. The containers were stored at $20{ }^{\circ} \mathrm{C} \pm 1{ }^{\circ} \mathrm{C}$. Over a period of two weeks, the beads were weighed daily until their weight was stable. They were assumed to be in equilibrium with their environment when the weight variation of a sample was less than $2 \%$ compared with the previous weight. We used the protocol proposed by Selmer-Olsen et al. (1999) to determine bead water content. The beads in each airtight container were placed in glass cups that had been weighed and dried for $1 \mathrm{~h}$ in an oven. The cups were put into an oven (Memmert, Schawabach, Germany) at $100{ }^{\circ} \mathrm{C}$ for $4 \mathrm{~h}$, and then recovered and cooled in a desiccator before being weighed. The water content was calculated from the mass difference between the two weightings.

Alginate bead size characterization. In order to study the influence of $\mathrm{RH}$ on bead size, the alginate bead radius was measured because this parameter has a role in the theoretical equation of diffusion in a sphere (Eq. 1). For this experiment, an easy-to-use photographic device (Figure 1c) that ensured constant conditions for taking pictures was constructed. The device consisted of a closed chamber in which two spotlights were placed facing each other to ensure constant quality lighting. A hole in the upper part of the chamber was used to connect it to a camera (Canon EOS 350D with an 18-5 mm lens). Alginate beads were placed on a black background under the camera lens and isolated from each other. A small blue patch $\left(1 \mathrm{~cm}^{2}\right)$ was put on the black background as reference for measurement. To enable the software

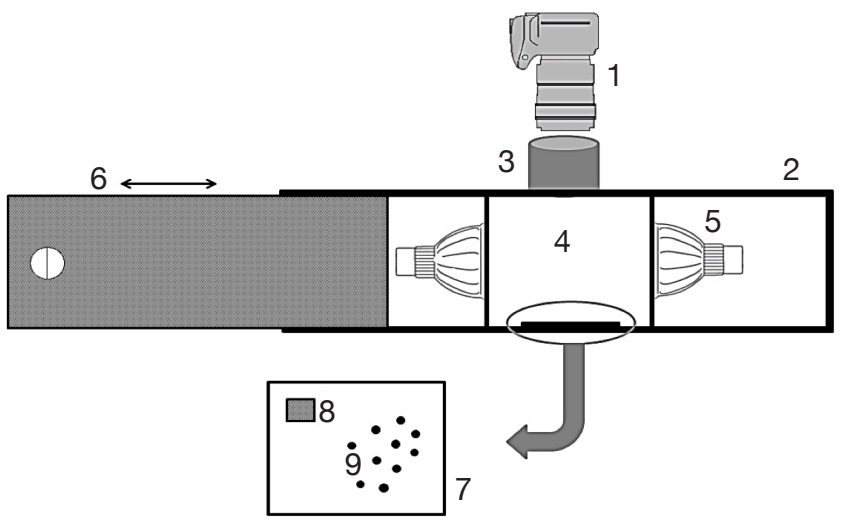

Figure 1c. Diagram of the photographic device - Schéma du dispositif de photographie.

1: camera - appareil de photographie; 2 : wooden box - boite en bois; 3: PVC tubing - tube en PVC; 4: closed chamber in which alginate beads are placed - chambre dans laquelle sont disposées les billes d'alginate; 5: spotlight - spot d'éclairage; 6: sliding wall - paroi coulissante; 7: black background - support noir; 8: blue patch - étalon de surface bleu; 9: alginate beads - billes d'alginate.

to differentiate the various constituents, the colors of the beads, background and layer needed to differ. The image processing was done with a script developed using Matlab vR2007b software. Using various picture parameters and morphologic treatments, the script isolated the beads from the rest of the picture and determined their dimensions.

The beads used in this experiment came from the same airtight containers used for the sorption isotherm determination described earlier.

\subsection{Data analyses}

The Box-Behnken experimental results were analyzed using a quadratic stepwise regression based on the following second-order equation (Eq. 2):

$$
Y=\mathrm{A}_{0}+\sum_{i=1}^{3} A_{i} X_{i}+\sum_{i=1}^{3} A_{i i} X_{i}^{2}+\sum_{i=1}^{2} \sum_{j=1+1}^{3} A_{i j} X_{i} X_{j}
$$

where $Y$ stands for diffusion coefficient $(D) ; \mathrm{A}_{0}$ is the constant of the model; $X_{i}$ and $X_{j}$ are the coded variables; $X_{i} X_{j}$ and $X_{i}^{2}$ represent the interaction and quadratic terms, respectively; and $A_{i}, A_{i i}$ and $A_{i j}$ are the coefficients of the linear, quadratic and interactive terms, respectively. Statistical analysis was performed using Student's $T$-test and Fisher's $F$-test. $P$-value $<0.05$ was regarded as significant.

Analysis of variance (ANOVA) and the TukeyKramer HSD test $(\alpha=0.05)$ were used to highlight any 
significant effect of RH on bead size. All the statistical analyses were performed using JMP® 7 statistical software (SAS institute, Cary, US) and Microsoft Excel software (Microsoft ${ }^{\circledR}$, Diegem, Belgium).

\section{RESULTS AND DISCUSSION}

\subsection{Impact of climatic factors on $\boldsymbol{E}-\boldsymbol{\beta}$ - caryophyllene release from alginate beads}

The development of a VCS and the establishment of an experimental design revealed that the diffusion coefficients of $E$ - $\beta$-caryophyllene fell between $2.0^{*}$ $10^{-15}$ and $5.6^{*} 10^{-14} \mathrm{~m}^{2} \cdot \mathrm{s}^{-1}$ for any climatic condition (Table 1). These values were of the same order of magnitude as those presented by Heuskin et al. (2012b), where the diffusion coefficients varied from $1.2 * 10^{-15}$ to $1.0^{*} 10^{-14} \mathrm{~m}^{2} \cdot \mathrm{s}^{-1}$. Our values were also close to the estimated diffusion coefficients obtained by Hambleton et al. (2011) for aroma diffusion in coating materials (alginate films) where the diffusion coefficients in the air of two aroma compounds, D-limonene and $n$-hexanal, varied from $6.0^{*} 10^{-16}$ to $7.6^{*} 10^{-16} \mathrm{~m}^{2} \cdot \mathrm{s}^{-1}$ for D-limonene and from $1.3 * 10^{-15}$ to $1.4 * 10^{-15} \mathrm{~m}^{2} \cdot \mathrm{s}^{-1}$ for $n$-hexanal. Our $E$ - $\beta$-caryophyllene diffusion coefficients were slightly higher than those for D-limonene and similar to those for $n$-hexanal. The values obtained in our experiment were also lower than those reported in other studies (Velings et al., 1996; Grassi et al., 2001; Lian et al., 2004), but the diffusion coefficients were calculated for compounds released in a solution rather than in the air. It is difficult to compare the different devices because of the variety of molecules used and the difference between the concept and formulation of the diffusion systems. In addition, the interactions between volatile compound and the polymer network of the encapsulation matrix can differ greatly from one compound to another (Velings, 1997). There is very little information on the calculation of diffusion coefficients for estimating the volatile molecule release rate in the air from alginate beads.

Analysis of Box-Behnken experiment. A secondorder polynomial model was fitted to describe the correlation between diffusion coefficients and the three climatic factors involved in this study - temperature $\left(X_{1}\right), \mathrm{RH}\left(X_{2}\right)$ and wind speed $\left(X_{3}\right)$ :
The statistical significance of Eq. 3 was checked using the $F$-test, and the ANOVA results are shown in table 2. The model $F$-value of 7.23 obtained by ANOVA indicated that the model was significant ( $p$-value $\left.<0.0056^{*}\right)$. The lack of fit $F$-value of 1.57 and associated $p$-value of 0.4413 was not significant, indicating that no lack of matching between the data and the model can be shown. For the fitted model, the coefficient of determination $\left(\mathrm{R}^{2}\right)$, an indicator of model performance, was $80.06 \%$, implying that only $19.94 \%$ of the total variation could not be explained by the model. These results suggest that the proposed model adequately represent a large part of the real relationship between the chosen factors in the range of selected values.

Effects of temperature, relative humidity and wind speed on $E$ - $\beta$-caryophyllene diffusion coefficient. As shown in table 2, temperature was the only factor that had a significant impact on the $E$ - $\beta$-caryophyllene release rate from the alginate beads. This climatic factor had a significant linear and quadratic effect on the $E-\beta$ caryophyllene diffusion coefficient $(p$-value $<0.05)$ in the range of the tested experimental conditions. The positive regression coefficient sign for temperature indicated that when the temperature increased, $E-\beta$ caryophyllene release from the alginate beads increased too. In fact, when the wind speed and RH were set, it was obvious that the diffusion coefficient increased with temperature, mainly for low RH values (Figures 2a and $\mathbf{2 b}$ ). This finding accorded with results obtained for other environmentally friendly devices described in the literature (Van der Kraan et al., 1990; Torr et al., 1997; Atterholt et al., 1999; Johansson et al., 2001; Shem et al., 2009; Zhu et al., 2015) and in the first study conducted by Heuskin et al. (2012b) on the alginate bead release system. Temperature had a direct impact on the evaporation of volatile molecules in the air (Krüger et al., 2002).

For the two other climatic factors, no significant statistical effect on the diffusion coefficient of $E-\beta$ caryophyllene from beads was found in the range of selected values. As shown in figure 2a, however, when temperature and wind speed were set, an increase in $\mathrm{RH}$ led to a slight decrease in sesquiterpene diffusion from the alginate beads. In their study on the release of semiochemicals from alginate beads, however, Heuskin et al. (2012b) demonstrated a significant impact of RH on diffusion. When RH exceeded $85 \%$, the sesquiterpene release stopped. This observation

$Y=1.0928+1.3575 X_{1}-0.6600 X_{2}+0.4475 X_{3}+1.3421 X_{1}^{2}-0.8500 X_{1} X_{2} \quad$ (Eq. 3) 
Table 2. Analysis of variance (ANOVA) of the response surface regression model for the diffusion coefficient (D) - Analyse de la variance (ANOVA) du modèle de régression de surface obtenu pour le coefficient de diffusion (D).

\begin{tabular}{|c|c|c|c|c|}
\hline \multicolumn{5}{|l|}{ Summary of fit } \\
\hline Rsquare & 0.800688 & & & \\
\hline Adj Rsquare & 0.68996 & & & \\
\hline Root Mean Square Error & 0.902431 & & & \\
\hline Mean of Response & 1.88667 & & & \\
\hline Observations (or Sum Wgts) & 15 & & & \\
\hline \multicolumn{5}{|l|}{ Analysis of variance } \\
\hline Source & Degree of freedom & Sum of squares & Mean square & F ratio \\
\hline Model & 5 & 29.444330 & 5.88887 & 7.2311 \\
\hline Error & 9 & 7.329443 & 0.81438 & Prob. $>$ F \\
\hline C. Total & 14 & 36.773773 & & $0.0056^{*}$ \\
\hline \multicolumn{5}{|l|}{ Lack of fit } \\
\hline Source & Degree of freedom & Sum of squares & Mean square & F ratio \\
\hline Lack Of Fit & 7 & 6.2062429 & 0.886606 & 1.5787 \\
\hline Pure Error & 2 & 1.1232000 & 0.561600 & Prob. $>$ F \\
\hline \multirow[t]{3}{*}{ Total Error } & 9 & 7.3294429 & & 0.4413 \\
\hline & & & & Max RSq \\
\hline & & & & 0.9695 \\
\hline \multicolumn{5}{|l|}{ Parameter estimates } \\
\hline Term & Estimate & Std error & T ratio & Prob. $>|t|$ \\
\hline Intercept & 1.0928571 & 0.341087 & 3.20 & $0.0108 *$ \\
\hline$X_{1}$ & 1.3575 & 0.319058 & 4.25 & $0.0021 *$ \\
\hline$X_{2}$ & -0.66 & 0.319058 & -2.07 & 0.0685 \\
\hline$X_{3}$ & 0.4475 & 0.319058 & 1.40 & 0.1943 \\
\hline$X_{1}^{2}$ & 1.3421429 & 0.467053 & 2.87 & $0.0184 *$ \\
\hline$X_{1} X_{2}$ & -0.85 & 0.451216 & -1.88 & 0.0922 \\
\hline
\end{tabular}

contradicts our finding in this experiment but in our study, the RH range used to estimate the diffusion coefficients of $E$ - $\beta$-caryophyllene was between 33 and $75 \%$. The maximum value was lower than the value for which a significant RH effect was observed by Heuskin et al. (2012b). The RH $p$-value was close to the limit value of 0.05 (Table 2), meaning that there could be an RH effect on the release rate. In addition, the negative regression coefficient sign for RH (Table 2) indicated that when the RH increased there was a decrease in $E$ - $\beta$-caryophyllene release, but this was not statistically proven.

In order to understand why Heuskin et al. (2012b) found an impact of $\mathrm{RH}$ on the semiochemical release rate whereas, in this study, no impact was found, sorption isotherms and an original observation of the impact of RH on bead size were determined for the first time using this type of slow-release device.

\subsection{Determination of alginate bead sorption isotherms}

Sorption isotherms can be determined using gravimetric and manometric methods. Arlabosse et al. (2003) considered that the manometric method is unsuitable for products containing a significant amount of volatile molecules. We therefore chose to use the supersaturated salt solutions method, which is common in the literature and has been used in many studies for several products (Arlabosse et al., 2003; Ferrasse et al., 2004; Rhim, 2004; Olivas et al., 2008).

Preliminary experiments. The preliminary tests on the alginate beads, with and without $E$ - $\beta$-caryophyllene, and on their components, showed that sunflower oil and vitamin $\mathrm{E}$ were not affected by drying process. There was a small decrease in mass in the alginate powder 


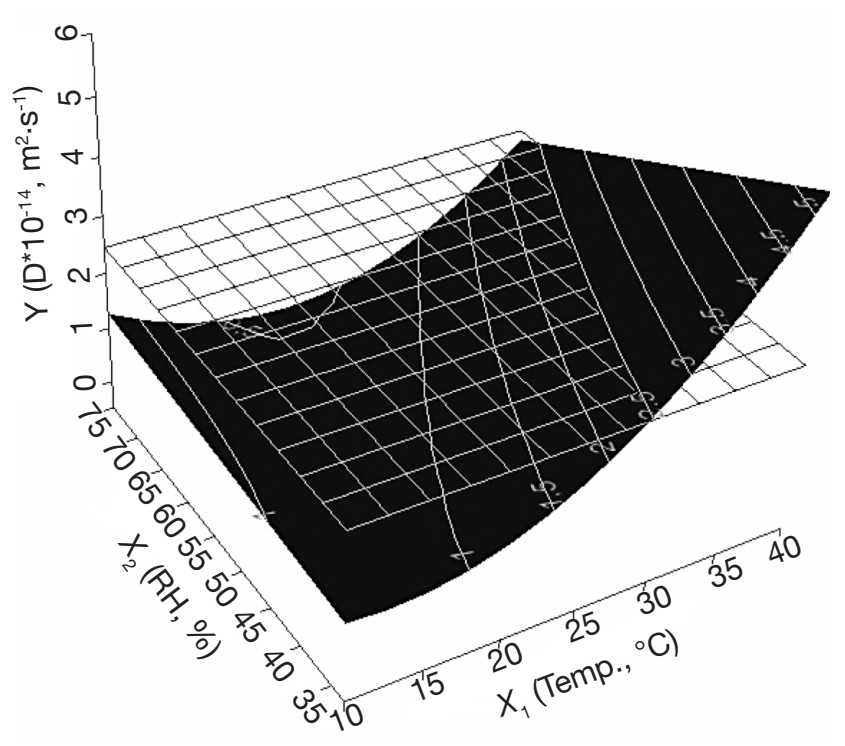

Figure 2a. Response surface plot showing the effect of temperature and $\mathrm{RH}$ on the diffusion coefficient (at a constant wind speed of $1.06 * 10^{-2} \mathrm{~m} \cdot \mathrm{s}^{-1}$ ) - Surface de réponse présentant les effets de la température et de l'humidité relative sur le coefficient de diffusion (vitesse du vent maintenue constante à $1,06^{*} 10^{-2} \mathrm{~m} \cdot \mathrm{s}^{-1}$ ).

and a significant decrease in mass in the alginate solution (data not shown). In the powder samples, the observed decrease was probably due to water getting into the alginate powder with the frequent handling of the bottle. The alginate solution samples were about $1.5 \%$ of their original mass. This value corresponds to the amount of alginate powder used in the alginate solution preparation (see $\S 2.2$.).

For beads with and without $E$ - $\beta$-caryophyllene, there was an important mass loss during the first $2 \mathrm{~h}$ of drying, with all the water in the alginate beads evaporating. After this, bead mass was stable for the remainder of the drying process. For beads with the $E$ - $\beta$ caryophyllene, there was a very small decrease in mass (less than $0.4 \%$ in weight variation compared with the previous weighing after $6 \mathrm{~h}$ ). This very low mass loss probably resulted from $E$ - $\beta$-caryophyllene release and could have led to a slight overestimation of the water content in the alginate beads. The difference between the two types of beads was negligible compared with the water lost during the first $2 \mathrm{~h}$ of drying (data not shown).

Water sorption isotherms. Sorption isotherms for alginate beads with and without $E$ - $\beta$-caryophyllene (Figure 3) showed a moisture content increase when RH ranged from 80 to $95 \%$. The general shape of the curves was exactly the same for the adsorption and desorption processes and the water content values obtained for the two bead types were relatively similar.

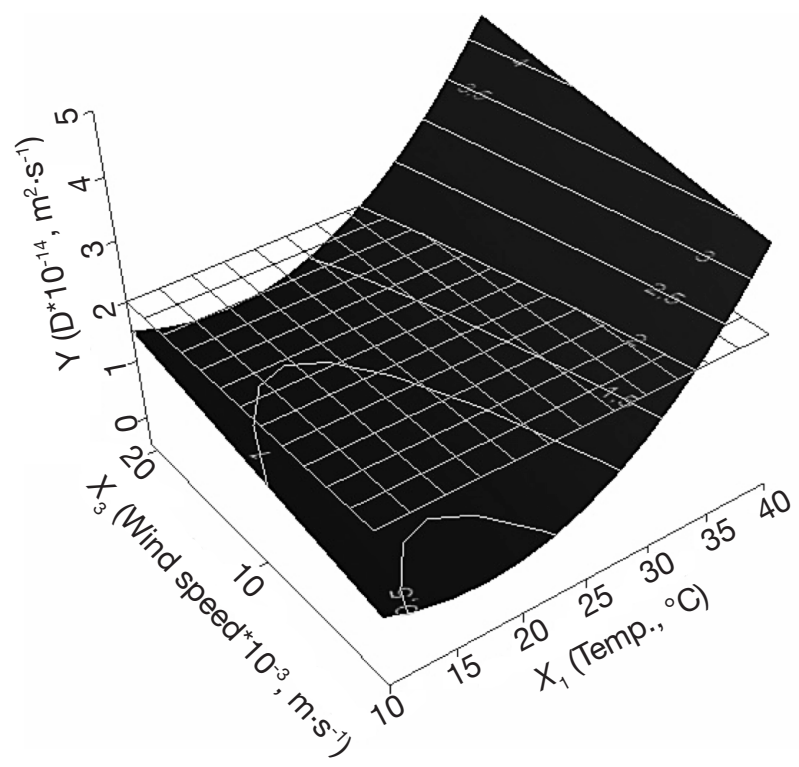

Figure 2b. Response surface plot showing the effect of temperature and wind speed on the diffusion coefficient (at a constant RH of 53\%) - Surface de réponse présentant les effets de la température et de la vitesse du vent sur le coefficient de diffusion (humidité relative maintenue constante à $53 \%$ ).

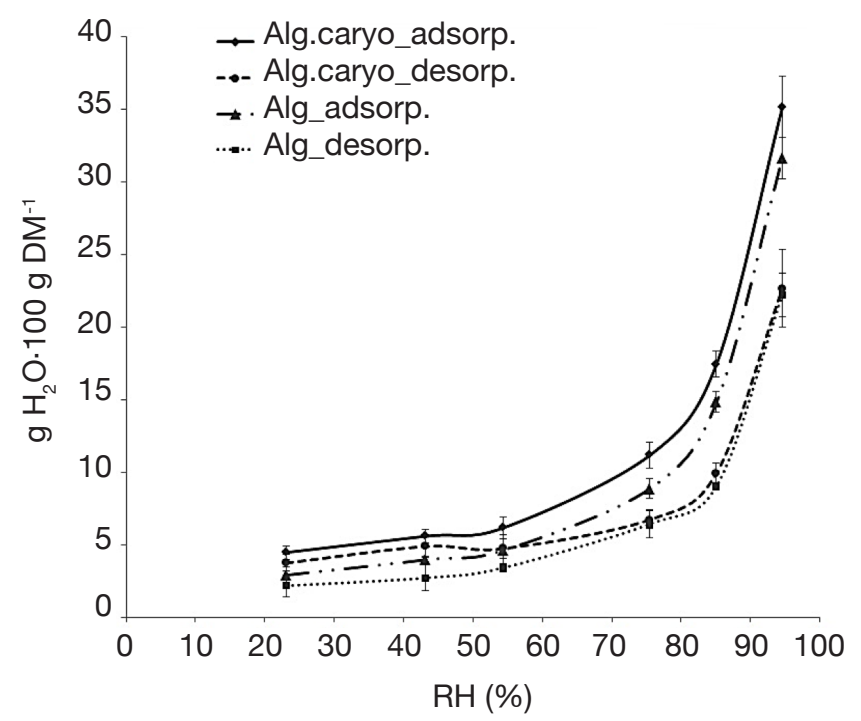

Figure 3. Sorption isotherms of alginate beads with and without $E$ - $\beta$-caryophyllene - Isothermes de sorption des billes d'alginate avec et sans E- $\beta$-caryophyllène.

Temperature was fixed at $20 \pm 1^{\circ} \mathrm{C}$ and there were three repetitions for each water content estimation (Alg: alginate; caryo: E- $\beta$-caryophyllene; adsorp.: adsorption isotherm; desorp.: desorption isotherm) - La température a été fixée à $20 \pm 1{ }^{\circ} \mathrm{C}$ et il y a eu trois répétitions pour chaque estimation de la teneur en eau (Alg : alginate ; caryo : E- $\beta$-caryophyllène ; adsorp. isotherme d'adsorption ; desorp. : isotherme de désorption). 
All the curves were concave upwards and presented a sigmoid shape, characteristic of the type II isotherms observed for many food products and biopolymer materials (Mathlouthi et al., 2003; Hambleton et al., 2012). Water content was always higher for the adsorption isotherms than the desorption isotherms. When $E$ - $\beta$-caryophyllene was incorporated into the alginate beads, water vapor uptake increased slightly. This could be explained by a slight overestimation of moisture content caused by the release of $E-\beta$ caryophyllene during drying in the oven. This slight overestimation was negligible. With this protocol it was possible to determine the general shape of the sorption isotherms for the beads with volatile compounds without systematically measuring the volatile molecule loss during drying. The results also showed that bead water content was relatively constant and less than $10 \mathrm{~g} \mathrm{H}_{2} \mathrm{O} \cdot 100 \mathrm{~g} \mathrm{DM}^{-1}$ over a wide range of $\mathrm{RH}$ values, from 0 to $70 \%$, but increased sharply from $80 \%$. It tripled between 70 and $90 \%$, reaching 25-30 $\mathrm{g} \mathrm{H}_{2} \mathrm{O} \cdot 100 \mathrm{~g} \mathrm{DM}^{-1}$ when the $\mathrm{RH}$ was about $90 \%$.

The shapes of the sorption isotherms were the same as those reported by Hambleton et al. (2012) for edible films, but in their study the incorporation of aroma reduced vapor uptake. The aroma compounds were relatively hydrophobic and the interactions between these molecules and the carbon chains reduced the number of sites available for hydrogen bonding. In our study, introducing $E$ - $\beta$-caryophyllene did not seem to disturb the vapor uptake properties of the calcium alginate matrix. In addition, when we compared the sorption isotherms of alginate beads with those of other alginate films, our water content was slightly lower than the others, although all values were of the same order of magnitude (Rhim, 2004; Olivas et al., 2008; Hambleton et al., 2012). In these other studies, water content was reported to be about 1 and $2 \mathrm{~g} \mathrm{H}_{2} \mathrm{O} \cdot \mathrm{g} \mathrm{DM}^{-1}$ for an RH set at 90 and $97 \%$, respectively. These slight differences probably resulted from the composition of the alginate solution, which differed in each study. The differences in alginate solution formulation make it difficult to compare the sorption isotherm curves obtained in various studies. All isotherm curves have the same shape, however, and it was clear that the vapor uptake properties were not affected by the shape of the alginate matrix.

The absence of a significant RH effect on the $E-\beta$ caryophyllene release rate could be explained with the alginate bead sorption isotherms. In the Box-Behnken experimental design, the three RH values used were all below $80 \%$. With the alginate bead sorption isotherms, therefore, it was clear that there was no significant change in bead water content in our selected range and therefore no significant effect on the $E$ - $\beta$-caryophyllene release rate could have been observed. These sorption isotherms also confirmed the microscopic observations made by Heuskin et al. (2012a), which revealed the presence of a thin liquid film surrounding the beads stored at an RH of $98 \%$, whereas there was no liquid film for beads stored at $42 \%$. In view of these findings, when $\mathrm{RH}$ exceeded $85 \%$ it was assumed that water absorbed by the alginate beads created a physical barrier to sesquiterpene release. $E$ - $\beta$-caryophyllene is a hydrophobic molecule and a change in bead water content could affect the diffusion of this volatile molecule and thus the effectiveness of the slow-release system.

In the field, $\mathrm{RH}$ is subjected to great variations from day to day, forcing alginate beads to go through many cycles of water absorption and desorption. This environmental constraint could compromise release efficiency. The beads' release efficiency over several water absorption-desorption cycles had already been proven and no significant effect on diffusion coefficients had been observed (Heuskin et al., 2012b). These results were interesting because they indicated that $E$ - $\beta$-caryophyllene release stops during rainy periods, when insects are less active, and restarts when the weather becomes drier. This effect of RH on the volatile compound release device could be used to maintain the beads during transport from manufacturers to farmers, avoiding excessive loss of semiochemicals before they are placed in fields. The diffusion coefficients calculated with Eq. 1 in our experiments and in the study by Heuskin et al. (2012b) could be called into question if the different RH values affected overall bead size. In using Eq. 1, it is important that the bead radius remains constant. We therefore developed an original photographic device and a script using Matlab software that would show whether or not the beads retained their original size, whatever the $\mathrm{RH}$ of the surrounding environment.

\subsection{Impact of relative humidity on alginate bead size}

For this experiment, 10 alginate beads were taken from each airtight container. This number of beads was chosen in line with the study conducted by Betigeri et al. (2002), where 10 beads were used to estimate the mean radius. This operation was carried out three times for each container.

The measured radii of alginate beads, with and without $E$ - $\beta$-caryophyllene, are shown in figures 4 a and $\mathbf{4 b}$, respectively. The bead radii, with or without $E$ - $\beta$-caryophyllene, were usually between 0.72 and $0.85 \mathrm{~mm}$. As a first step and only for beads containing $E$ - $\beta$-caryophyllene, a significant difference was shown between radii obtained at different RH values ( $p$-value: $0.0448)$. This finding could be questioned because this $p$-value was close to the critical value $(\alpha=0.05)$. In addition, when the mean radius was compared using 

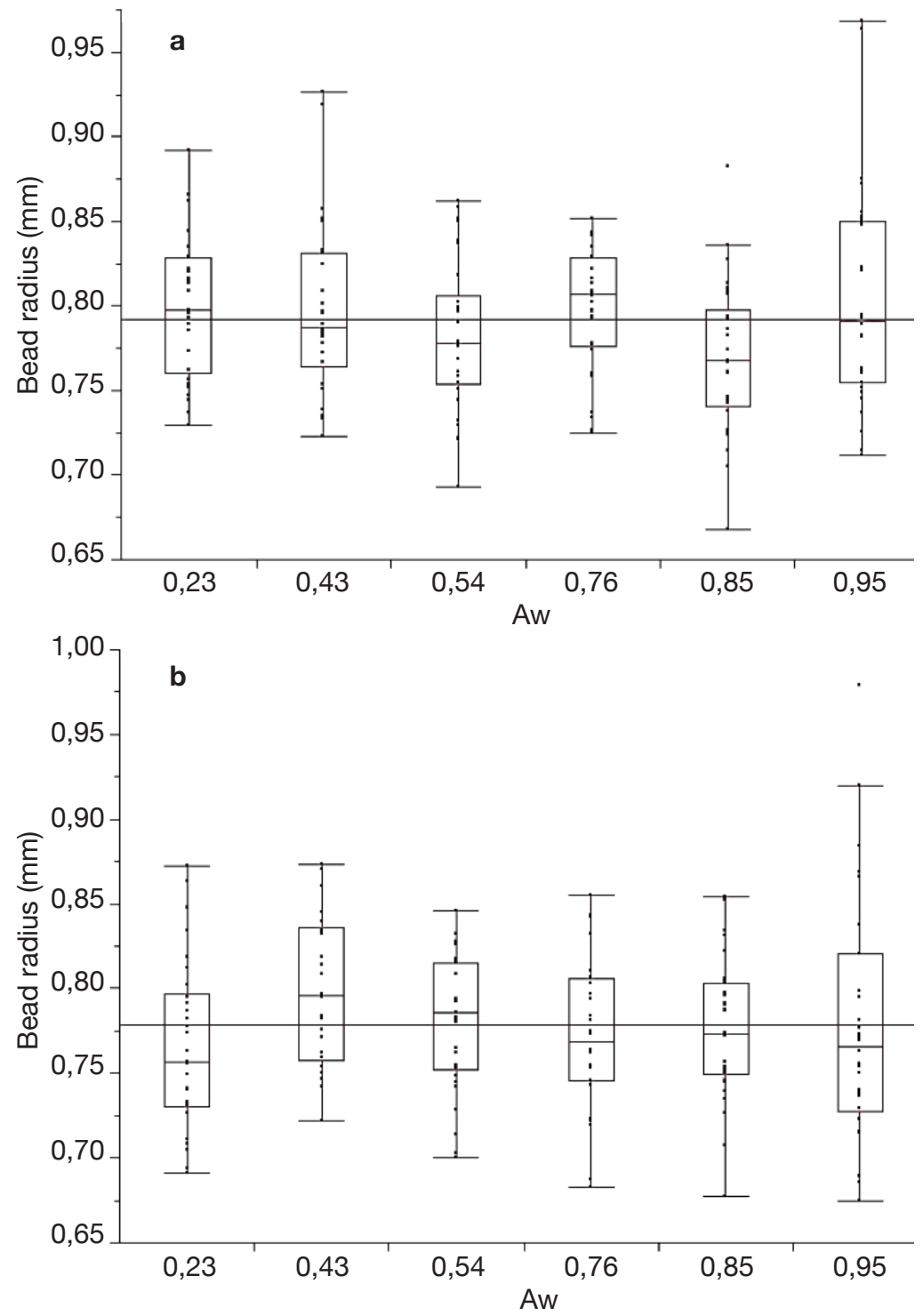

Figure 4. Illustration of the effect of RH on the alginate bead size. Boxplots of the alginate bead radii under various $\mathrm{RH}$ values are presented for beads with (a) and without (b) E- $\beta$-caryophyllene - Illustration de l'effet de l'humidité relative sur la taille des billes d'alginate. «Boxplots» pour les rayons des billes d'alginate avec $(\boldsymbol{a})$ et sans $(\boldsymbol{b}) \mathrm{E}-\beta$-caryophyllène.

the Tukey-Kramer HSD test, no significant difference between bead radii for the six RH values was found. This difference could be because, sometimes, some bead radii were much higher or lower than the mean of the others and these outliers had been detected in the first statistical treatment. The beads whose size did not conform to the mean were not numerous and probably arose from production problems. For beads without $E$ - $\beta$-caryophyllene, the ANOVA ( $p$-value: 0.1933) and Tukey-Kramer HSD test showed no significant difference.

In conclusion, therefore, the alginate beads kept their spherical shape regardless of the surrounding air
$\mathrm{RH}$. This finding is very important in the application of Eq. 1 for estimating diffusion coefficients. With this experiment, the radius of alginate beads produced in the laboratory was then accurately determined. The mean value was $0.79 \pm$ $0.05 \mathrm{~mm}(\mathrm{n}=360, \mathrm{RSD}=6.2 \%)$. This low RSD confirmed our conclusion that bead size was not influenced by RH. This value was then reintroduced in Eq. 1 in order to obtain a more accurate estimate of the diffusion coefficient of $E$ - $\beta$-caryophyllene (results shown in table 1).

\section{CONCLUSIONS}

This scoping study conducted at the laboratory scale clearly demonstrated that $E$ - $\beta$-caryophyllene release rates from alginate beads increased at higher temperatures, whereas neither $\mathrm{RH}$ nor airflow had a significant effect on the $E$ - $\beta$ caryophyllene release rate for values below $75 \%$ and $2.05 \times 10^{-2} \mathrm{~m} \cdot \mathrm{s}^{-1}$, respectively. Alginate bead sorption isotherms were also successfully derived for the first time and the general curve shape obtained was the most common one for food products and biopolymer materials. These isotherms support the suggestion by Heuskin et al. (2012b) that the presence of a physical water barrier stops $E$ - $\beta$-caryophyllene release from alginate beads when the $\mathrm{RH}$ exceeds $80-85 \%$. It was also shown that the beads kept their original size, whatever the $\mathrm{RH}$ of the surrounding environment. This means that the theoretical equation (Eq. 1) (Cranck, 1975) for diffusion in a sphere used to calculate the diffusion coefficient could be applied regardless of the $\mathrm{RH}$ of the environment in which alginate beads are placed.

This research has provided some initial information about the impact of climatic factors on $E-\beta$ caryophyllene released from alginate beads. In order to optimize the effectiveness of this slow-release device, these findings need to be confirmed in the field under natural conditions. The research also paves the way for more specific studies on the interactions between alginate networks and volatile compounds.

\section{Acknowledgements}

The authors are grateful to the staff of Food Science and Analytical Chemistry laboratories from Gembloux Agro-Bio 
Tech, University of Liège, for their active participation in this study.

\section{Bibliography}

Alhmedi A., Haubruge É. \& Francis F., 2010. Identification of limonene as a potential kairomone of the harlequin ladybird Harmonia axyridis (Coleoptera: Coccinellidae). Eur. J. Entomol., 107, 541-548.

Arlabosse P. et al., 2003. Comparison between static and dynamic methods for sorption isotherm measurements. Drying Technol., 21, 479-497.

Atterholt C.A., Delwiche M.J., Rice R.E. \& Krochta J.M., 1999. Controlled release of insect sex pheromones from paraffin wax and emulsions. J. Controlled Release, 57, 233-247.

Baucour P. \& Daudin J.D., 2000. Development of a new method for fast measurement of water sorption isotherms in the high humidity range validation on gelatin gel. J. Food Eng., 44, 97-107.

Betigeri S.S. \& Neau H.S., 2002. Immobilization of lipase using hydrophilic polymers in the form of hydrogel beads. Biomaterials, 23, 3627-3636.

Byers J., 1988. Novel diffusion-dilution method for release of semiochemicals: testing pheromone component ratios on Western Pine Beetle. J. Chem. Ecol., 14(1), 199-212.

Chang C.P. \& Dobashi T., 2003. Preparation of alginate complex capsules containing eucalyptus essential oil and its controlled release. Colloids Surface, B, 32, 257-262.

Cork A. et al., 2008. Development of a PVC-resin-controlled release formulation for pheromones and use in mating disruption of yellow rice stem borer. Crop Prot., 27, 248255.

Cox P.D., 2004. Potential for using semiochemicals to protect stored products from insect infestation. J. Stored Prod. Res., 40, 1-25.

Cranck J., 1975. The mathematics of diffusion. $2^{\text {nd }}$ ed. London: Oxford University Press, chapter 6, 89-103.

Davis T.A. et al., 2003. H-NMR study of $\mathrm{Na}$ alginates extracted from Sargassum spp. in relation to metal biosorption. Appl. Biochem. Biotechnol., 110(2), 75-90.

De Vlieger J.J., 2001. Development of a sprayable slowrelease formulation for the sex pheromone of the Mediterranean corn borer, Sesamia nonagroides. IOBC WPRS Bull., 24(2), 101-106.

Draget K.I., Skjak-Braek G. \& Smidsrod O., 1997. Alginate based new materials. Int. J. Biol. Macromol., 21, 47-55.

Ferrasse J.H. \& Lecomte D., 2004. Simultaneous heat-flow differential calorimetry and thermogravimetry for fast determination of sorption isotherms and heat of sorption in environmental or food engineering. Chem. Eng. Sci., 59, 1365-1376.

Golub M., Weatherston J.\& Benn M.H., 1983. Measurement of release rates of gossyplure from controlled release formulations by mini-airflow method. J. Chem. Ecol., 9(3), 323-333.
Grassi M., Colombo I. \& Lapasin R., 2001. Experimental determination of theophylline diffusion coefficient in swollen sodium-alginate membranes. J. Controlled Release, 76, 93-105.

Hambleton A., Voilley A. \& Debeaufort F., 2011. Transport parameters for aroma compounds through i-carrageenan and sodium alginate-based edible films. Food Hydrocolloids, 25(5), 1128-1133.

Hambleton A. et al., 2012. The Schroeder paradox or how the state of water affects the moisture transfer through edible films. Food Chem., 132, 1671-1678.

Hennesy P.J., Stipanovic A.J. \& Webster F., 2004. Microparticle dispensers for the controlled release of insect pheromones. J. Agric. Food Chem., 52(8), 2301-2308.

Heuskin S. et al., 2010. Validation of a gas chromatographic method for the study of semiochemical slow release formulations. J. Pharm. Biomed. Anal., 53, 962-972.

Heuskin S. et al., 2011. The use of semiochemical slowrelease devices in integrated pest management strategies. Biotechnol. Agron. Soc. Environ., 15(3), 459-470.

Heuskin S. et al., 2012a. Optimisation of a semiochemical slow-release alginate formulation attractive towards Aphidius ervi Haliday parasitoids. Pest Manage. Sci., 68, 127-136.

Heuskin S. et al., 2012b. A semiochemical slow-release formulation in a biological control approach to attract hoverflies. J. Environ. Ecol., 3(1), 72-85.

Hofmeyr J.H. \& Burger B.V., 1995. Controlled-release pheromone dispenser for use in traps to monitor flight activity of false codling moth. J. Chem. Ecol., 21(3), 355-363.

Horst R.K., 2013. Westcott's plant disease handbook. $8^{\text {th }} \mathrm{ed}$. Dordrecht, The Netherlands: Springer, 29-30.

Johansson B.G. et al., 2001. Release rates for pine sawly pheromones from two types of dispensers and phenology of Neodiprion sertifer. J. Chem. Ecol., 27, 733-745.

Kehat M. et al., 1994. Sex pheromone traps for monitoring the codling moth: effect of dispenser type, field aging of dispenser, pheromone dose and type of trap on male captures. Entomol. Exp. Appl., 70(1), 55-62.

Kogan M., 1998. Integrated pest management: historical perspectives and contemporary developments. Аnnu. Rev. Entomol., 43, 243-270.

Krüger A.J. \& Tolmay A.T., 2002. Prediction of the release characteristics of alcohols from EVA using a model based on Fick's second law of diffusion. J. Appl. Polym. Sci., 84, 806-813.

Lai F. et al., 2007. Artemesia arborescens L. essential oil loaded beads: preparation and characterization. AAPS PharmSciTech, 8(3), E1-E7.

Lian G., Malone M.E., Homan J.E. \& Norton I.T., 2004. A mathematical model of volatile release in mouth from the dispersion of gelled emulsion particles. J. Controlled Release, 98, 139-155.

Lopez J.D., Leonhardt B.A. \& S Shaver T.N., 1991. Performance criteria and specifications for laminated 
plastic sex pheromone dispenser for Helicoverpa zea (Lepidoptera: Noctuidae). J. Chem. Ecol., 17(11), 22932305.

Malone M.E. \& Appelqvist I.A., 2003. Gelled emulsion particles for the controlled release of lipophilic volatiles during eating. J. Controlled Release, 90, 227-241.

Mathlouthi M. \& Rogé B., 2003. Water vapour sorption isotherms and the caking of food powders. Food Chem., 82, 61-71.

McDonough L.M, 1991. Controlled release of insect sex pheromones from a natural rubber substrate. In: Hedin P.A., ed. Naturally occurring pest bioregulators. Washington: American Chemical Society, 106-124.

Olivas G.I. \& Barbosa-Cánovas G.V., 2008. Alginatecalcium films: water vapor permeability and mechanical properties as affected by plasticizer and relative humidity. LWT Food. Sci. Technol., 41, 359-366.

Rao M.A. \& Rizvi S.S.H., 1995. Engineering properties of foods. $2^{\text {nd }}$ ed. New York, USA: Marcel Dekker, 242.

Reddy G.V.P. \& Guerrero A., 2004. Interactions of insect pheromones and plant semiochemicals. Trends Plant Sci., 9(5), 253-261.

Rhim J.W., 2004. Physical and mechanical properties of water resistant sodium alginate films. LWT Food. Sci. Technol., 37, 323-330.

Sasso R. et al., 2009. Electrophysiological and behavioural responses of Aphidius ervi (Hymenoptera: Braconidae) to tomato plant volatiles. Chemoecology, 19, 195-201.

Selmer-Olsen E., Sorhaug T., Birkeland S.E. \& Pehrson R., 1999. Survival of Lactobacillus helveticus entrapped in $\mathrm{Ca}$-alginate in relation to water content, storage and rehydration. J. Ind. Microbiol. Biotechnol., 23, 79-85.

Shem P.M. et al., 2009. Release kinetics of a synthetic tsetse allomone derived from waterbuck odour from a Tygon silicon dispenser under laboratory and semi field conditions. Am. Eurasian J. Agric. Environ. Sci., 6(6), 625-636.

Suckling D.M., Green S.R., Gibb A.R. \& Karg G., 1999. Predicting atmospheric concentration of pheromone in treated apple orchards. J. Chem. Ecol., 25(1), 117-139.

Tapia D.H., Morales F. \& Grez A.A., 2010. Olfactory cues mediating prey-searching behavior in interacting aphidophagous predators: are semiochemicals key factors in predator-facilitation? Entomol. Exp. Appl., 137, 28-35.

Tomaszewska E. et al., 2005. Evaluation of pheromone release from commercial mating disruption dispensers. J. Agric. Food Chem., 53, 2399-2405.
Tomova B.S., Waterhouse J.S. \& Boberski J., 2005. The effect of fractionated Tagetes oil volatiles on aphid reproduction. Entomol. Exp. Appl., 115, 153-159.

Torr S.J., Hall D.R., Phelps R.J. \& Vale G.A., 1997. Methods for dispensing odour attractants for tsetse flies (Diptera: Glossinidae). Bull. Entomol. Res., 87, 299-311.

Van der Kraan C. \& Ebbers A., 1990. Release rates of tetradecen-1-ol acetates from polymeric formulations in relation to temperature and air velocity. J. Chem. Ecol., 16, 1041-1058.

Velings N., 1997. Propriétés physico-chimiques des billes d'alginates et leur influence sur l'incorporation ou le relargage de molécules bioactives. Thèse de doctorat: Université catholique de Louvain, Louvain-la-Neuve (Belgique).

Velings N. \& Mestdagh M., 1995. Physico-chemical properties of alginate gel beads. Polym. Gels Networks, 3, 311-330.

Velings N., Ouwerx C., Mestdagh M. \& Axelos M., 1996. Physico-chemical properties of alginate gel beads and their incidence on retention/release of proteins. In: Proceedings of the $5^{\text {th }}$ International Workshop on Bioencapsulation, from fundamentals to industrial applications, September 23-25, 1996, Postdam, Germany, talk 37.

Welter S.C. et al., 2005. Pheromone mating disruption offers selective management option for key pests. California Agric., 59(1), 16-22.

Witzgall P., 2001. Pheromones - future techniques for insect control? Pheromones for insect control in orchards and vineyards. IOBC WPRS Bull., 24(2), 114-122.

Yosha I., Shani A. \& Magdassi S., 2008. Slow release of pheromones to the atmosphere from gelatin-alginate beads. J. Agric. Food Chem., 56, 8045-8049.

Zada A., Falach L. \& Byers J.A., 2009. Development of sol-gel formulations for slow release of pheromones. Chemoecology, 19, 37-45.

Zhang A. et al., 2008. Activity evaluation of cocoa pod borer sex pheromone in cacao fields. Environ. Entomol., 37(3), 719-724.

Zhu H. et al., 2015. Measurement of semiochemical release rates with a dedicated environmental control system. Biosyst. Eng., 129, 277-287. 